\title{
Impact of the COVID-19 Outbreak on Emergency Resources - An Observational Multicenter Study Including All Hospitals in a Major Urban Center of the Rhein Ruhr Metropolitan Region
}

Sebastian Bergrath ( $\nabla$ sebastian.bergrath@mariahilf.de)

Kliniken Maria Hilf GmbH https://orcid.org/0000-0001-5297-7655

\section{Tobias Strapatsas}

Emergency Department, Städtische Kliniken Mönchengladbach, Germany

\section{Michael Tuemen}

Emergency department, Bethesda Krankenhaus Mönchengladbach, Germany

Thorsten Reith

Emergency department, Krankenhaus Neuwerk, Mönchengladbach Germany

\section{Marc Deussen}

Fire department, City of Mönchengladbach, Germany

\section{Olaf Aretz}

Emergency Department, Kliniken Maria Hilf Mönchengladbach, Germany

\section{Andreas Hohn}

Department of Anaesthesiology, Kliniken Maria Hilf, Mönchengladbach, Germany

\section{Andreas Lahm}

Department of Orthopdic Surgery, University Hospital RWTH Aachen, Germany

\section{Original research}

Keywords: COVID-19, Rhein Ruhr Metropolitan region, emergency resources, urban center

Posted Date: October 29th, 2020

DOl: https://doi.org/10.21203/rs.3.rs-97392/v1

License: (c) (i) This work is licensed under a Creative Commons Attribution 4.0 International License. Read Full License 


\section{Abstract}

Background: The outbreak of the coronavirus disease 2019 (COVID-19) caused by the severe respiratory distress syndrome coronavirus 2 (SARS-CoV-2) led to severe disruption in social life and economics. The present study should analyze the impact of the local COVID-19 epidemic on emergency resources for all hospitals in a major urban center (Moenchengladbach, Germany).

Methods: An observational multicenter study was performed involving all four acute care hospitals. Systemic parameters department (ED) parameters from week 4 to 24 in 2020 were compared to the corresponding period in 2019 for each hospital and in a summative data analysis using a logistic regression model. Outcomes: ED visits, ED to hospital admission, ED to Intensive Care Unit (ICU) admission, medical specialties of admitted patients, work related accidents.

Results: In week 9/2020 the first SARS-CoV-2 positive patients were detected in our region. All hospitals decided to minimize elective admissions to ensure operational capability for COVID-19 patients. The summative number of ED visits dropped from 34,659 to 28,008. Numbers decreased from week 8 on between $38 \%$ and $48 \%$ per week per hospital at the maximum and began to rise again from week 16 on. The pooled data analysis showed statistically significant decreases in outpatient ED visits $(20,152$ vs. $16,477, p=<0.001)$, hospital admissions of ED patients ( 14,507 vs. $11,531, p=<0.001)$, and work-related accidents $(2,290$ vs. $1,468, p=<0.001)$. The decrease in admissions from ED to ICU did not reach statistical significance $(2,093$ vs. $1,566, p=0.255)$. The decline in $E D$ cases was mainly caused by a decrease in non-trauma and non-surgical patients.

Conclusion: The regional COVID-19 outbreak led to significantly reduced ED contacts after the first COVID-19 cases appeared. Even the admissions to the hospitals and the number of ED to ICU-admissions decreased, which is potentially dangerous, because the ratio of emergency outpatients vs. inpatients remained stable. Therefore, one can assume that patients with severe medical problems did not seek ED care in many cases. The decline of patients was earlier than in other German hospitals and in contrast to the findings in the U.S. and Italy where ED visits and hospital admissions in medical disciplines increased.

\section{Introduction}

In week 9 of 2020 the Coronavirus disease (COVID-19) reached the German region of Heinsberg and this region became an epidemic hotspot regarding infections with the severe respiratory distress syndrome virus-2 (SARS-CoV-2) within a few days. The city of Moenchengladbach $(274,096$ residents, $12-2019)$ is located nearby and has four academic teaching hospitals with different specializations and numbers of hospital beds (Table 1).

COVID-19 became a widespread problem in Germany in March 2020 so that multiple interventions where conducted to reduce virus spreading. Beside public interventions like social distancing, closure of restaurants and non-food stores also in-hospital interventions like a visiting ban were executed by the 
national and local politicians. All hospitals in our city adapted their processes of out- and in-patient treatment and tried to expand their resources for treatment of SARS-CoV-2 positive patients.

Redistributions of in-hospital resources led to transformed processes and changed priorities in allocation of hospital staff and hospital beds to ensure admission of SARS-CoV-2 positive and suspicious patients. It was already shown that it some German hospitals - mainly university hospitals - the number of emergency department (ED) visits dropped significantly [1]. These hospitals were specialized hospitals in different regions of the country. It remains unclear how the COVID-19 outbreak influenced a whole metropolitan area with its complete hospital resources and how ED patient characteristics differed compared to the pre-COVID period.

Against this background, we carried out a retrospective multicenter pre-post study to analyze how the local COVID-19 outbreak, together with corresponding media reports and changes in public life, influenced the systemic parameters and emergency medicine indicators of all acute hospitals in an entire German city.

\section{Methods}

\section{Study design}

This observational multicenter analysis was performed retrospectively after the first wave of SARS-CoV-2 infections in Germany. All data were collected prospectively in the medical controlling departments and the hospital information systems of the participating hospitals. To evaluate possible influences of the COVID-19 outbreak, the time period from week 4 to 24 in 2020 was compared to the corresponding period in 2019.

\section{Study cites}

All acute care hospitals in the city of Moenchengladbach, Germany participated (Table 1). Every hospital runs an ED and one to five intensive-care units.

\section{Outcomes}

The following parameters and key figures were analyzed for each hospital as well as for the whole city in a pooled analysis:

- total number of ED visits

- number of hospital admissions from the ED

- number of outpatient contacts in the ED

- hospital admissions related to the different medical specialities

- number of ICU-admissions from the ED

- number of working accidents 
These parameters should be shown in relation to the time of the following events: appearance of the first SARS-CoV-2 cases in the region, social distancing measures, case numbers of SARS-CoV-2 positive patients in Mönchengladbach and Easter holidays.

The medical disciplines are summarized as follows: Internal medicine, including all subspecialties; traumatology; surgery other than traumatology (visceral surgery, vascular surgery, plastic surgery, spine surgery) and others (including gynecology and obstetrics, urology, pediatrics, ENT medicine, geriatrics, nuclear medicine, therapeutic radiology).

\section{Ethical approval}

Data collection was performed after ethical approval by the ethics committee of the University Hospital RWTH Aachen, Germany (EK 251/20) and registration at the Clinical Trials Center Aachen (registration number CTC-A 20-297) was conducted.

\section{Data sources and statistical analyses}

Data were retrieved from the medical controlling department (Kliniken Maria Hilf) or from the hospital information system using a data export tool (all other hospitals) and transferred to an Excel database (Excel, Microsoft Corp., Redmond, WA, USA). Data comprised no personal patient data. Data of the local COVID-19 numbers were retrieved from the Center of health of the state of Northrhine Westfalia and from the information system of security of the state of Northrhine Westfalia [2,3].

We conducted a local polynomial regression. Statistical analyses were performed using R software (V. 4.02; R Core Team, Vienna, Austria, https://www.R-project.org/). Data related to the first COVID-19 outbreak from week 4 to 24 in 2020 were compared to the corresponding period in 2019 using Chi-Square test for each hospital for the whole period and in weekly periods. When multiple comparisons were calculated, Bonferroni-Holm correction was used to adjust p-values. To account for local peculiarities, we pooled all data and compared both periods for all city hospitals data.

\section{Results}

In all hospitals, large decreases in overall ED visits with relative reductions between 38 and $48 \%$ were detected (Figure $1 \mathrm{~A}$ ). In hospital number 4 electronic documentation of ED visits started within the historical control period of 2019 and therefore, data of hospital 4 were not included in the pooled analysis. Overall ED visits declined from 34,659 to 28,008 cases. The maximum of reduced ED visit was found in week 14 of 2020 and at the end of the study period ED visits were 17\% lower compared to the corresponding week in 2019. The local decline of patients varied between the hospitals that were included in the pre-post analysis (hospital 1-3) and decreases up to $40 \%$ were detected (Figure 1B). Patient numbers declined behind each other: hospital $3-2-1$ (Figure 1). Outpatient ED visits dropped 
from 20,152 (2019) to 16,477 (2020), $\mathrm{p}=<0.001$ (Figure 2), but in hospital number 1 there were only few changes in outpatient contacts. Also hospital admissions of ED patients declined from 14,507 to 11,531, $\mathrm{p}=<0.001$ (Figure 2). The decrease in admissions mainly affected medical admissions. Traumatology and emergency surgical admissions were less affected during the COVID-19 crisis (Figure 3). Admissions from ED to intensive care unit (ICU) dropped from 2,093 to 1,566, $p=0.255$, but in contrast to all other evaluated parameters there was no significant difference prior to the COVID-19 outbreak. Data of ICU admissions were mainly affected by hospital 3 with its 52 ICU beds because the number of ICU admissions from the ED of hospital 3 approximately counts as much as the rest together. Work related accidents showed a dynamic trend in 2019 with a decrease in the spring and increase after Easter holidays but the decrease in 2020 was more profound and the curve did not recover after Easter holidays like it recovered in 2019 after the Easter holidays: 2,290 (2019) vs. 1,468 (2020), $p=<0.001$.

The local COVID-19 situation was as follows: In the city of Moenchengladbach there were 650 SARS-CoV2 positive patients in the study period of 2020 . With 577 recovered patients and 41 deaths due to or related to COVID-19 at the end of the study period. Structured data acquisition of in-hospital patients began at March $18^{\text {th }} 2020$ in a state-wide register [3]. Between week 12 and week 24 all hospitals treated 175 patients as SARS-CoV-2 positive inpatients. It has to be mentioned that in the hospitals of Moenchengladbach not only residents of this city were treated for COVID-19. Also, patients of neighboring districts (Heinsberg, Viersen, Rhein-Kreis Neuss) including 2 patients from the Netherlands were admitted.

\section{Discussion}

The COVID-19 outbreak led to significantly reduced overall emergency room visits and hospital admissions from the ED. This decrease in patients seeking emergency medical care mainly affected medical specialties while numbers of trauma patients and emergent surgical patients dropped noticeably less. Even though statistically not significant, admissions from the ED to the ICU dropped although more ICU resources were available due to adapted in-hospital processes. This decrease of hospital admissions is alarming because not only outpatients with minor medical problems avoided ED medical care, but also inpatient numbers dropped which is supported by the ratio of outpatients vs. inpatients that remained the similar. This phenomenon - probably mostly due to patient's fear of SARS-CoV-2 - was also described by Wong et al. and led to an increased number of cardiac arrests in the Californian region [4].

To our knowledge, our study is the first evaluating the changes on emergency care in a whole city in Europe observed during the COVID-19 outbreak. The local effects in the analyzed hospitals were very different due to the different sizes and specializations (table 1, figures 1-4).

Data from the U.S. also showed that reductions in ED visits were observed while admission to the hospital from ED increased between to $22 \%$ and $149 \%$ when the SARS-CoV-2 case rate began to increase [5]. The same effect was reported by Comelli et al. in Parma, Italy in a large urban ED [6]. These findings are in contrast to our findings, but the analyzed U.S. and Italian regions were hit much harder by the 
pandemic with more SARS-CoV-2 hospital admissions related to the residents. In Italy, also the incidence of prehospital cardiac arrest increased during the COVID-19 pandemic. Fear of infection with a consecutive delay in seeking medical care is also one of the possible reasons for these findings [7]. Another difference to our findings is that in a recent U.S. supra-regional study the ED visits dropped with a latency after the SARS-CoV-2 infections began to rise [8]. In the analyzed city of Moenchengladbach, ED visits declined after local media published the first local COVID-19 cases. Also in other German hospitals, reduced ED visits during the pandemic crisis were found which is also in contrast to the U.S. and Italia but data was retrieved from an ED register of mainly university hospitals which is not completely representative [1]. In contrast to this study that included data of 36 different German hospitals in different regions, the decrease of patients seeking medical care in an ED in our study dropped two weeks earlier [1]. In week 9, after the first cases of SARS-CoV-2 positive patients relating to an indoor carnival event (Gangelt, district of Heinsberg, Germany) were launched by the local press, ED visits began to drop in our city. The local press also launched that one hospital doctor in hospital 3 was infected with SARS-CoV-2. [9] Later on, media published hospital staff infections in hospital 2 [10]. This information could be one important reason for the accelerated local drop of ED visits and earlier decrease compared to other German regions [1].

Like described above, the decrease in admitted patients was mainly due to declined patient numbers in medical disciplines and much less in trauma and concerning other surgical emergency cases. Schwarz et al. also describe reduced ED visits due to cardiovascular emergencies in a German university hospital, but cerebrovascular accidents did not decrease significantly [11]. Quadri et al describe reduced laboratory procedures in Italy, even for percutaneous coronary interventions [12]. This holds the risk that even patients with an urgent need for a percutaneous coronary intervention do not seek cardiovascular medical care.

Overall, German data seem to be in contrast to the most U.S. data of COVID-19 hotspots where medical admissions from the ED increased and motor vehicle accidents decreased $[5,8,13]$. Also in Israel significant reductions in ED visits were observed [14]. The reduction was even more profound compared with H1N1 epidemic in 2009 in this region [14].

Working accidents dropped also in spring of 2019, especially during Easter holiday, but recovered thereafter. In 2020 the decrease in working accidents began earlier parallel to the social distancing measures like school and non-food store closures. A considerable amount of working accidents are accidents of pupils in all kind of schools or childcare facilities. Therefore, the closure of schools and kindergartens could be one explanation for the declined number of working accidents. Unfortunately, we were not able to differentiate between accidents at workplaces and accidents at schools. Nunez et al. report that ED visits for trauma, workplace accidents and road traffic accidents declined significantly compared to the same period in 2019 during the Coronavirus crisis at a tertiary hospital in Spain [15]. In many hospitals orthopedic trauma capacities were adapted (mainly reduced and/or re-organized) due to increased numbers of COVID-19 patients [16]. 
After a period with restaurant, non-food-store and school closure the social life in Germany came to an adapted normality during May 2020. However, the number of ED visits did not recover to the numbers of 2019. One explanation could be that people still fear to be infected with SARS-CoV-2 in hospitals.

\section{Limitations}

One major limitation is that partially data of one hospital could not be included in the pooled analysis because structured data acquisition started in 2019 during the historical control period. Therefore, all sum-curves are affected by this limitation. Our study is a retrospective data analysis with all limitations, but we did not analyze any performance or outcome data. Missing data of ED contacts and hospital admissions are very unlikely, but we cannot exclude missing data completely. Contact times and length of stay in the ED could not be analyzed due to different documentation systems and different use of time stamps. Therefore, we cannot answer the question, if the COVID-19 outbreak affected the ED treatment time span and turnaround times.

\section{Conclusion}

Patient numbers seeking medical care in EDs dropped significantly after the first SARS-CoV-2 positive patients and hospital staff were launched by the local media in a German major urban center. The decline in patients affected not only patients with minor medical problems but also the number of hospital admissions form the ED and even the number of patients admitted to the ICU which is in contrast to U.S and Italian data. The decline is alarming because it reinforces the suspicion that patients with relevant medical problems did not seek medical care due to possible fear of infection. We need to publish information campaigns that in-hospital medical care is safe during the COVID-19 pandemic, because the pandemic will probably last for a longer time and critically ill patients should seek medical immediately.

\section{Declarations}

\section{Ethics approval and consent to participate}

Data collection was performed after ethical approval by the ethics committee of the University Hospital RWTH Aachen, Germany (EK 251/20) and registration at the Clinical Trials Center Aachen (registration number CTC-A 20-297) was conducted.

\section{Availability of data and materials}

The datasets used and analyzed during the current study are available from the corresponding author on reasonable request.

\section{Competing Interests}

The authors declare no conflict of interest regarding this study. 


\section{Funding}

There was no specific funding for the conducted study.

\section{Author's contributions}

$\mathrm{SB}, \mathrm{TS}, \mathrm{AH}$ and $\mathrm{AL}$ designed the study. SB, TS, MT, TR and MD performed data collection. Ethics approval was obtained by SB and AL. Study registration was conducted by SB and AL. TS and SB performed statistical analysis of data. SB, TS, AL and AH wrote the manuscript draft. Tables and Figures were designed by TS, SB, MT and TR. Data analysis and the interpretation was conducted by all authors. MT, $A H, T S, M D$ and $A L$ critically revised the manuscript. All authors read and approved the final version of the manuscript.

\section{References}

1. Slagman A, Behringer W, Greiner F, Klein M, Weismann D, Erdmann B, et al. Medical Emergencies During the COVID-19 Pandemic. Dtsch Arzteblatt Int. 2020;117:545-52.

2. Corona-Meldelage - LZG.NRW [Internet]. [cited 2020 Oct 4]. Available from: https://www.lzg.nrw.de/inf_schutz/corona_meldelage/index.html

3. Information system for security in the state of Northrhine Westfalia (IG-NRW) [Internet]. Available from: https://ig.nrw.de

4. Wong LE, Hawkins JE, Langness S, Iris P, Sammann A. Where Are All the Patients? Addressing Covid19 Fear to Encourage Sick Patients to Seek Emergency Care. 2020;12.

5. Molly M J, Gail D, Hyung P, Timothy P-M, William S, Jason H, et al. Trends in Emergency Department Visits and Hospital Admissions in Health Care Systems in 5 States in the First Months of the COVID19 Pandemic in the US. JAMA Intern Med. JAMA Intern Med; 2020;e203288.

6. Comelli I, Scioscioli F, Cervellin G. Impact of the COVID-19 epidemic on census, organization and activity of a large urban Emergency Department. Acta Bio-Medica Atenei Parm. 2020;91:45-9.

7. Baldi E, Sechi GM, Mare C, Canevari F, Brancaglione A, Primi R, et al. Out-of-Hospital Cardiac Arrest during the Covid-19 Outbreak in Italy. N Engl J Med. 2020;

8. Boserup B, McKenney M, Elkbuli A. The impact of the COVID-19 pandemic on emergency department visits and patient safety in the United States. Am J Emerg Med. 2020;38:1732-6.

9. Richters AG Sabine Janssen, Denisa. Kliniken Maria Hilf in Mönchengladbach: Klinik-Arzt mit Coronavirus infiziert [Internet]. RP ONLINE. [cited 2020 Sep 26]. Available from: https://rponline.de/nrw/staedte/moenchengladbach/coronavirus-in-moenchengladbach-arzt-an-klinikenmaria-hilf-infiziert_aid-49207507

10. Gruhn A. Ärztin am Elisabeth-Krankenhaus ist infiziert: Zwei weitere Corona-Fälle in Mönchengladbach bestätigt [Internet]. RP ONLINE. [cited 2020 Sep 26]. Available from: https://rponline.de/nrw/staedte/moenchengladbach/coronavirus-moenchengladbach-zwei-weitere-faellebestaetigt_aid-49272801 
11. Schwarz V, Mahfoud F, Lauder L, Reith W, Behnke S, Smola S, et al. Decline of emergency admissions for cardiovascular and cerebrovascular events after the outbreak of COVID-19. Clin Res Cardiol Off J Ger Card Soc. 2020;

12. Quadri G, Rognoni A, Cerrato E, Baralis G, Boccuzzi G, Brsic E, et al. Catheterization laboratory activity before and during COVID-19 spread: A comparative analysis in Piedmont, Italy, by the Italian Society of Interventional Cardiology (GISE). Int J Cardiol. 2020;

13. Goyal P, Choi JJ, Pinheiro LC, Schenck EJ, Chen R, Jabri A, et al. Clinical Characteristics of Covid-19 in New York City. N Engl J Med. 2020;

14. Fuat B, Hisam Z, Khetam H, Shlomo H. Drastic Reduction Inpatient Visits to the Emergency Department in a Hospital in Israel During the COVID-19 Outbreak, Compared to the H1N1 2009. Int J Health Policy Manag. Int J Health Policy Manag; 2020;doi: 10.34172/ijhpm.2020.151. Online ahead of print.

15. Nuñez JH, Sallent A, Lakhani K, Guerra-Farfan E, Vidal N, Ekhtiari S, et al. Impact of the COVID-19 Pandemic on an Emergency Traumatology Service: Experience at a Tertiary Trauma Centre in Spain. Injury. 2020;51:1414-8.

16. Tahmassebi R, Bates P, Trompeter A, Bhattacharya R, El-Daly I, Jeyaseelan L, et al. Reflections from London's Level-1 Major Trauma Centres during the COVID crisis. Eur J Orthop Surg Traumatol Orthop Traumatol. 2020;30:951-4.

\section{Table}


Table 1.

Characteristics and key figures of participating hospitals

\begin{tabular}{|c|c|c|c|c|}
\hline $\begin{array}{l}\text { hospital / } \\
\text { parameters }\end{array}$ & $\begin{array}{l}\text { Evangelisches } \\
\text { Krankenhaus } \\
\text { Bethesda } \\
\text { (Hospital 1) }\end{array}$ & $\begin{array}{l}\text { Städtische Kliniken } \\
\text { Mönchengladbach } \\
\text { St. Elisabeth } \\
\text { (Hospital 2) }\end{array}$ & $\begin{array}{l}\text { Kliniken Maria Hilf } \\
\text { (Hospital 3) }\end{array}$ & $\begin{array}{l}\text { Krankenhaus } \\
\text { Neuwerk "Maria } \\
\text { von den Aposteln" } \\
\text { (Hospital 4) }\end{array}$ \\
\hline $\begin{array}{l}\text { Number of } \\
\text { hospital } \\
\text { beds }\end{array}$ & 350 & 547 & 754 & 310 \\
\hline $\begin{array}{l}\text { Emergency } \\
\text { room beds }\end{array}$ & 10 & 20 & 35 & 10 \\
\hline $\begin{array}{l}\text { ED } \\
\text { resuscitation } \\
\text { rooms }\end{array}$ & 1 & 2 & $3 / 4^{*}$ & 1 \\
\hline $\begin{array}{l}\text { High-care } \\
\text { ICU beds }\end{array}$ & 13 & 25 & 52 & $12^{*}$ \\
\hline $\begin{array}{l}\text { Low-care } \\
\text { ICU beds }\end{array}$ & 4 & 0 & 4 & 4 \\
\hline $\begin{array}{l}\text { Cardiac } \\
\text { catheter } \\
\text { laboratory } \\
24 / 7\end{array}$ & yes & yes & yes & no \\
\hline $\begin{array}{l}\text { Chest pain } \\
\text { unit }\end{array}$ & 6 beds & 10 beds & 8 beds & 0 \\
\hline Stroke unit & no & no & $\begin{array}{l}18 \text { beds, } \\
\text { supraregional stroke } \\
\text { center }\end{array}$ & no \\
\hline $\begin{array}{l}\text { Trauma } \\
\text { center }\end{array}$ & no & level 2 (regional) & level 2 (regional) & level 1 (local) \\
\hline $\begin{array}{l}\text { Medical } \\
\text { specialties }\end{array}$ & 8 & 15 & 17 & 9 \\
\hline $\begin{array}{l}\text { Pediatric } \\
\text { emergency } \\
\text { care }\end{array}$ & no & $\begin{array}{l}\text { yes, including } \\
\text { pediatric ICU }\end{array}$ & $\begin{array}{l}\text { only for trauma, } \\
\text { abdominal surgery } \\
\text { ENT and urology }\end{array}$ & yes \\
\hline obstetrics & yes & yes, Level 1 & no & yes \\
\hline
\end{tabular}

ICU, intensive care unit; ENT, ears, nose and throat medicine; * number after adaption due to COVID-19 outbreak

\section{Figures}




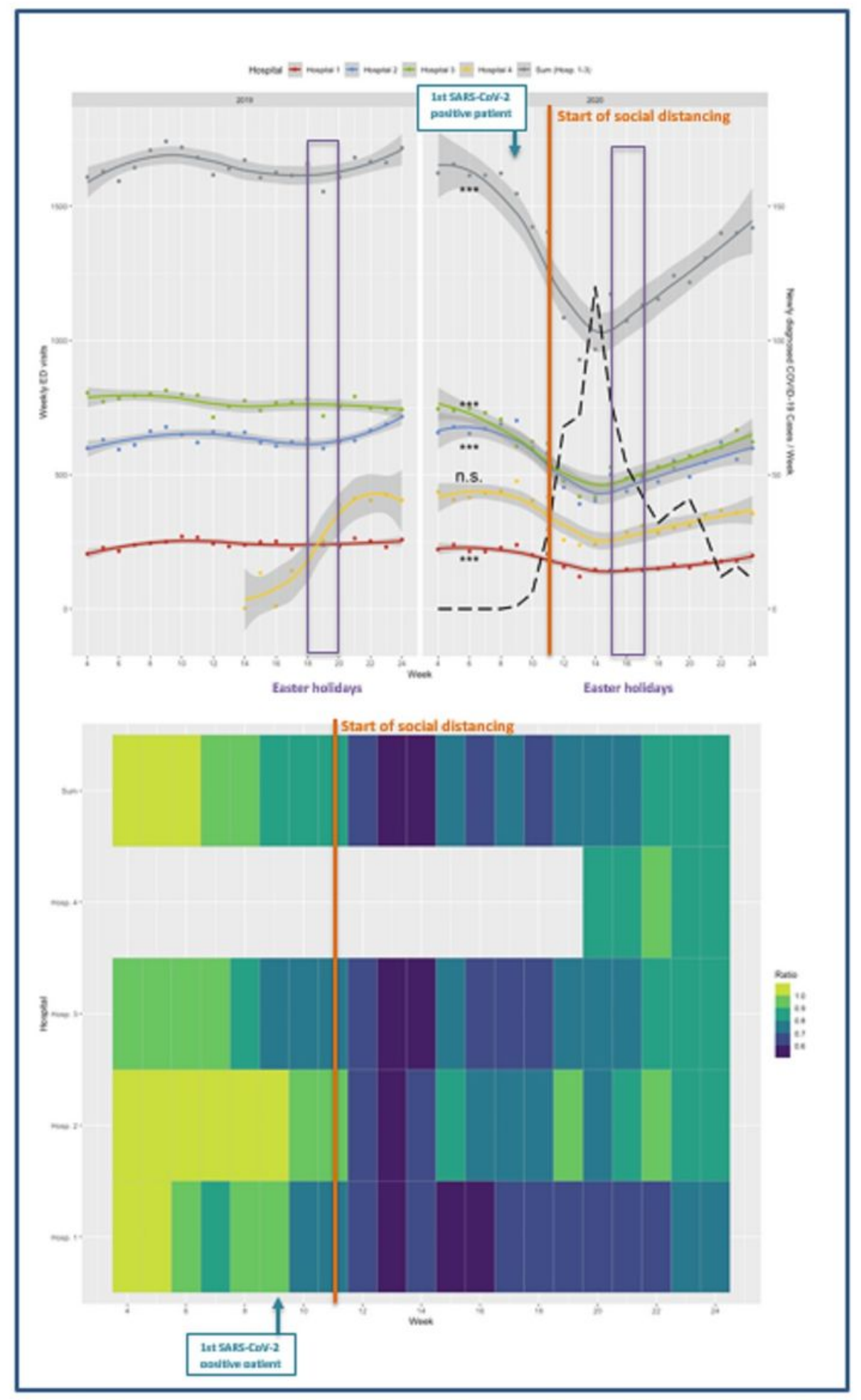

\section{Figure 1}

A: Weekly numbers of ED visits for all four hospitals in 2019 (right) and 2020 (left). The plotted black line shows newly diagnosed COVID-19 cases per week. Hospital 4 is not included in the sum, because electronic data acquisition began in week 14 of 2019. B: relative changes in ED visits as heatmap with ratio between 2020 and 2019 per week. The plotted black line shows newly diagnosed COVID-19 cases per week. ${ }^{*}=p<0.05 ;{ }^{* *}=p<0.01^{* * *}=p<0.001$; n.s. $=$ non-significant 


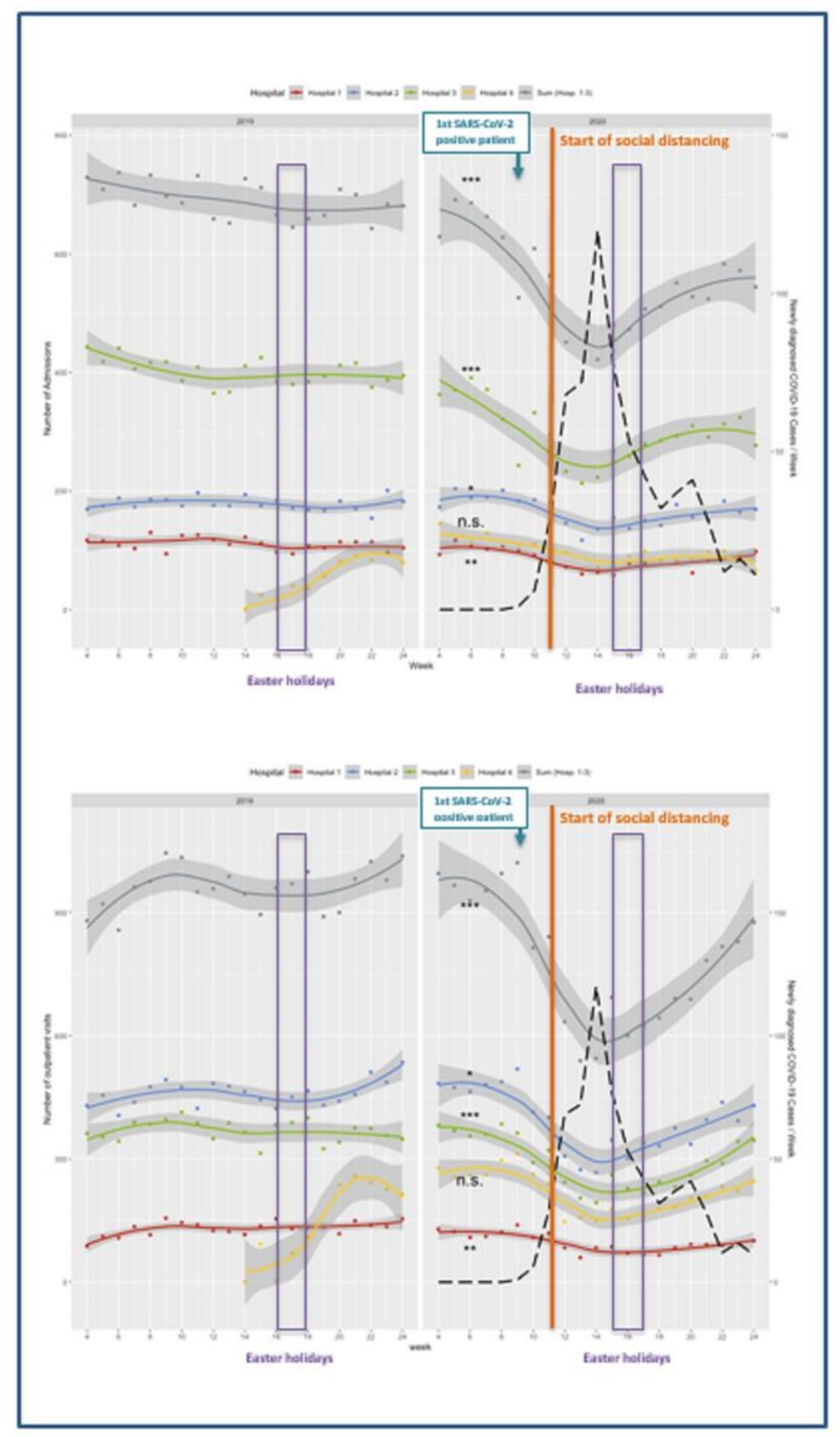

\section{Figure 2}

Weekly numbers of hospital admissions from the ED and numbers of outpatient cases in the ED for all four hospitals (sum of hospital 1-3) in 2019 (right) and 2020 (left). Hospital 4 is not included in the sum, because electronic data acquisition began in week 14 of 2019. The plotted black line shows newly diagnosed COVID-19 cases per week. ${ }^{*}=p<0.05 ;{ }^{* \star}=p<0.01^{\star \star \star}=p<0.001 ;$ n.s. $=$ non-significant 

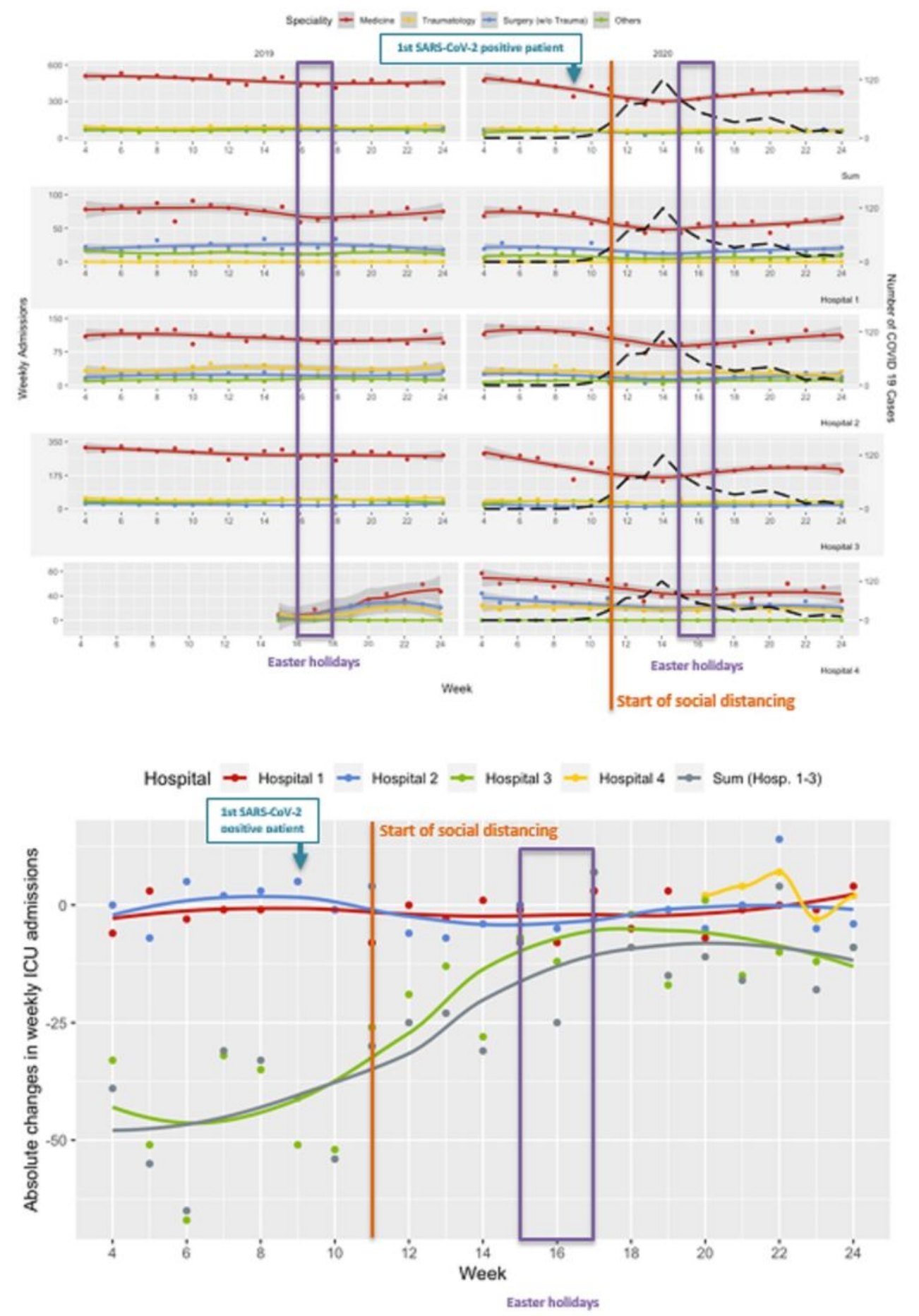

\section{Figure 3}

A Grouped medical specialty of hospital admissions from the ED for the sum (hospital 1-3) and for each hospital. B Relative changes (\%) of ICU admissions from the ED resuscitation room. The plotted black line shows newly diagnosed COVID-19 cases per week. ${ }^{*}=p<0.05 ;{ }^{* \star}=p<0.01^{\star \star \star}=p<0.001 ;$ n.s. $=$ nonsignificant 


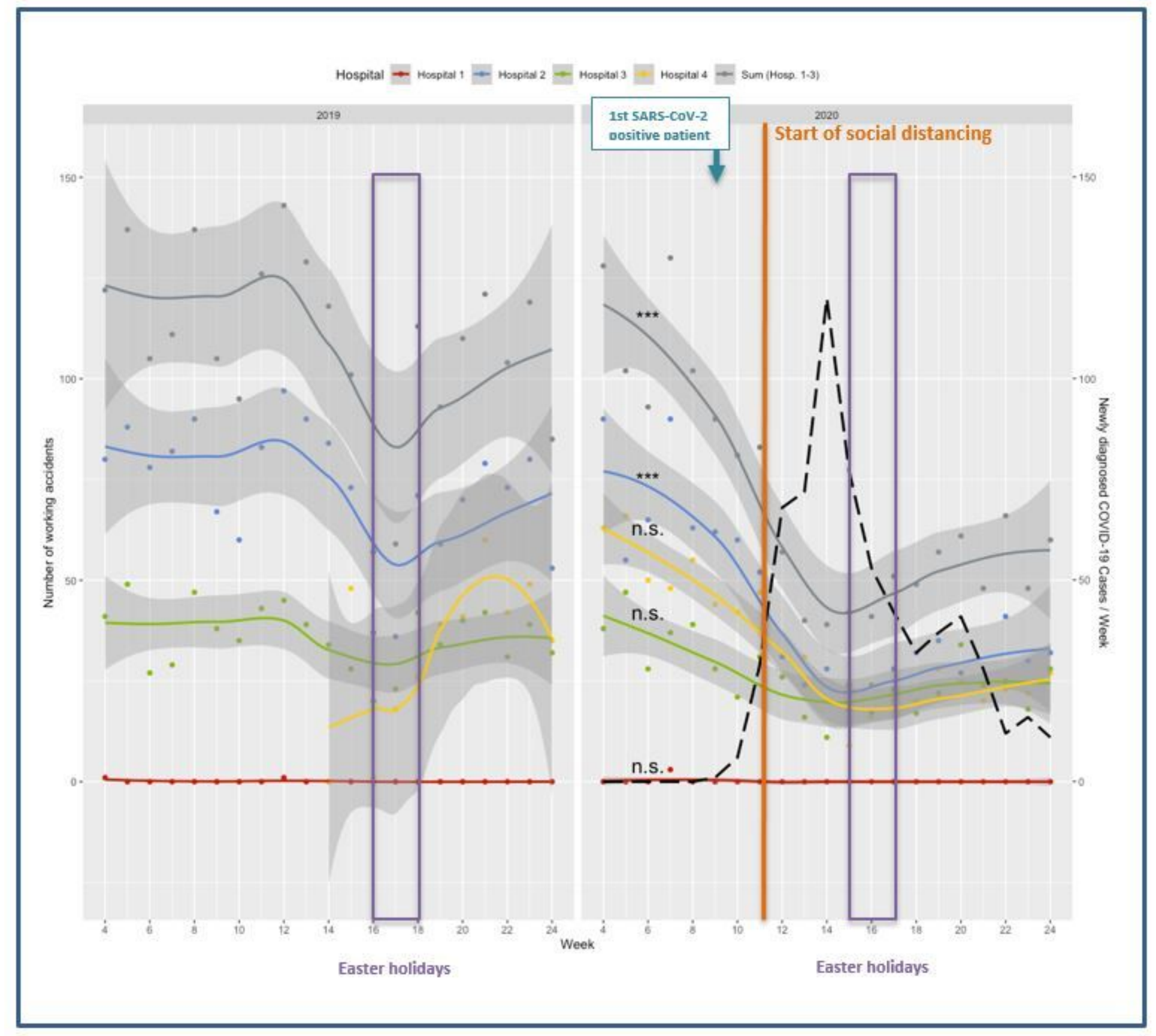

\section{Figure 4}

Number of working accidents for each hospital and the sum (hospital 1-3). The plotted black line shows newly diagnosed COVID-19 cases per week. ${ }^{*}=p<0.05 ;{ }^{* *}=p<0.01^{\star \star \star}=p<0.001 ;$ n.s. $=$ non-significant 